\title{
DISCRIMINACIÓN SALARIAL POR GÉNERO EN EL MERCADO DE TRABAJO DEL PARAGUAY: ANÁLISIS DEL SECTOR FORMAL, ZONA METROPOLITANA Y ZONA FRONTERIZA CON BRASIL ${ }^{\circ}$
}

\author{
SALARY DISCRIMINATION BY GENDER IN THE LABOR \\ MARKET OF PARAGUAY: ANALYSIS OF THE FORMAL SECTOR, \\ METROPOLITAN AREA AND BORDER AREA WITH BRAZIL
}

\author{
Débora de Lima Braga Penha* \\ Aníbal David Cuenca López** \\ Francisco Carlos da Cunha Cassuce ${ }^{* * *}$
}

enviado: 13 abril 2020 - aceptado: 22 julio 2020

\begin{abstract}
Resumen
Este estudio tiene por objeto analizar el comportamiento de la discriminación salarial por género del mercado laboral paraguayo del sector formal con foco en la zona metropolitana y fronteriza con Brasil durante el período 2017 a 2019. Para tal efecto, se estimaron las ecuaciones de salarios de Mincer (1974) y la metodología de Heckman (1979). Posteriormente, se realiza la descomposición de Oaxaca-Blinder (1973). Los resultados indican que pese a la disminución de la brecha salarial en el período analizado aún persisten las desigualdades de ingresos por género. Parte de la brecha de ingresos se debe a factores no explicados, que podrían atribuirse a la

Braga Penha, D. L., Cuenca López, A. D., \& da Cunha Cassuce, F. C. (2021). Discriminación salarial por género en el mercado de trabajo del Paraguay: análisis del sector formal, zona metropolitana y zona fronteriza con Brasil. Estudios económicos, 38(76), 5-43.

* Universidade Federal de Viçosa. Correo electrónico: debinha443@gmail.com. ORCID: https://orcid. org/0000-0002-5820-3009

** Universidade Federal de Viçosa. Correo electrónico: acuenca0591@gmail.com. ORCID: https:// orcid.org/0000-0001-5163-528

*** Universidade Federal de Viçosa. Correo electrónico: francisco.cassuce@ufv.br. ORCID: https:// orcid.org/0000-0002-7545-3747
\end{abstract}


discriminación. Por esta razón, es necesario implementar políticas que garanticen la igualdad salarial por sexo.

Palabras clave: discriminación salarial, género, sector formal, Paraguay. Códigos JEL: J71, J31, C01.

\begin{abstract}
The objective of this study is to analyze the wage discrimination's behavior based on gender in the Paraguayan labor market in the formal sector, focusing on the metropolitan region and the border with Brazil in the period from 2017 to 2019. For this purpose, the wage equations were estimated of Mincer (1974) and Heckman's (1979) methodology. Subsequently, the Oaxaca-Blinder decomposition (1973) is performed. The results indicate that, despite the fall in the wage gap in the analyzed period, income inequalities by gender still persist. Part of the income gap is due to unexplained factors that can be attributed to discrimination. For this reason, it is necessary to implement policies that guarantee equal pay for sex.
\end{abstract}

Keywords: wage discrimination, gender, formal sector, Paraguay. JEL Codes: J71, J31, C01. 


\section{INTRODUCCIÓN}

Según la Organización de las Naciones Unidas (ONU) la discriminación se refiere a la distinción, exclusión, restricción o preferencias basadas en el nivel socioeconómico, la condición étnico-racial, la religión, el ciclo de vida, la nacionalidad u origen, la opinión política, así como los sesgos de género, entre otros factores, que tenga por objeto o por resultado anular o menoscabar el reconocimiento, goce o ejercicio, en condiciones de igualdad, de los derechos humanos y libertades fundamentales de todos los individuos (CEPAL, 2019; Gelover \& Garmendia, 2005).

En esa perspectiva, la discriminación puede ser trasladada al ámbito laboral pudiendo afectar el tipo de trabajo que desempeña y el salario que percibe el individuo. En ese aspecto, Castillo (2011) menciona que la discriminación salarial se caracteriza cuando individuos con iguales capacidades perciben salarios diferenciados debido a factores que no están relacionados con la productividad del trabajador sino a otros aspectos como el sexo, la raza, etnia, etc.

De este modo, la discriminación y exclusión laboral de las mujeres puede ocasionar diversas consecuencias como la creación de barreras que impidan el pleno desarrollo económico-social de las mujeres debido a la baja participación política y escasa toma de decisiones; deserción del mercado de trabajo por maternidad; segregación ocupacional en actividades consideradas femeninas como de servicios que son menos valorizados; obstaculización a las mujeres para alcanzar mayores niveles jerárquicos en las empresas e instituciones; disminución de la inversión en capital humano, así como un menor nivel de ahorro para el período de jubilación (AlbujaEcheverría \& Enríquez-Rodríguez, 2018; Castro Lugo, Huesca Reynoso, \& Zamarrón Otzuca, 2015; Fuentes, Palma, \& Montero, 2005; Meza Martínez, 2018).

Por otro lado, Oliveira \& Piccinini (2011) establecen la existencia de segmentos de mercado que no compiten entre sí para acceder a los puestos laborales. La segmentación de mercado establece la remuneración diferenciada del capital humano debido a la existencia de barreras de entrada que impiden que todos se beneficien igualmente del mismo nivel de educación y entrenamiento. En ese sentido, el funcionamiento del mercado se divide en dos grandes segmentos, el sector formal caracterizado por la seguridad laboral, salarios elevados, oportunidad de ascenso, y el mercado informal caracterizado por la falta de regulación, puestos de trabajo con baja remuneración, escasas oportunidades de ascenso (FernándezHuerga, 2010). 
Asimismo, los mecanismos y características del mercado formal e informal son diferentes una vez que las decisiones en materia de trabajo se consideran determinantes por factores de la oferta como la demanda. Por tanto, a pesar de las decisiones de los individuos de trabajar o no en un determinado puesto laboral, existen restricciones por el lado de la demanda del mercado laboral, como escasez de empleos de buena calidad (García \& Badillo, 2018). En ese caso, el sector formal está avalado por contratos formales para realizar funciones a cambio de una remuneración presente y futura, y prestaciones de seguridad social, lo cual son elementos esenciales para el bienestar socioeconómico y la reducción de las desigualdades (Ehrenberg \& Smith, 2017; Rodríguez-Pérez, Ramos-Lobo, \& Castro-Lugo, 2017; Silva \& Kassouf, 2000).

A partir de lo anterior, se considera que el sector formal ofrece una mayor protección a los empleados ante cambios que puedan surgir en la economía, además de empleos mejor remunerados conforme a las características productivas del individuo. Por lo tanto, el presente trabajo tiene como problema de investigación responder a la siguiente pregunta: ¿cómo se manifiesta la discriminación salarial por género en el mercado de trabajo formal del Paraguay durante el período 2017 a 2019?

Cabe resaltar que la informalidad del mercado laboral paraguayo se caracteriza por la falta de contratos laborales sujetos a las leyes vigentes del país que garanticen el cumplimiento de todos los derechos de los trabajadores. En ese sentido, un individuo que trabaja por cuenta propia se encuentra en el mercado formal si está registrado en el Registro Único del Contribuyente (RUC), del mismo modo, un individuo que es empleado público o privado se encuentra en el sector formal si aporta a un sistema de seguridad social o pensión (Fernández, 2015; ONU MUJERES, 2015; PNUD, 2013).

Por otro lado, se emplea el análisis de las regiones o zonas económicamente más desarrolladas del país, que son la zona metropolitana y la fronteriza con Brasil. La elección de las zonas de análisis se debe a la importancia económica y comercial para el país, siendo las regiones con mayor dinamismo económico.

La razón para realizar esta clasificación se debe al hecho de que Paraguay es un país bastante heterogéneo desde el punto de vista económico-social y tiene un vínculo comercial muy grande con Brasil (Banco Mundial, 2019; OCDE, 2018; Servin \& Masi, 2018). De este modo, es posible analizar el efecto del mayor dinamismo económico y apertura comercial sobre la discriminación salarial por género, dado que no existen estudios previos relacionados con el tema de investigación. En este sentido, las diferencias regionales contribuyen fuertemente 
a aumentar la desigualdad salarial entre los individuos debido al tamaño y grado de complejidad de la estructura urbana (Campante, Crespo, \& Leite, 2004; Corseuil, Fernandes, Menezes-Filho, Coelho, \& Santos, 2002; Menezes, Carrera-Fernandez, \& Dedecca, 2005; Silveira Braga \& Rodarte, 2006). Así también, Rodríguez-Pérez \& Castro-Lugo (2014) señalan que la disparidades regionales son significativas, y además, que la heterogeneidad entre las regiones son persistentes debido a elementos estructurales que permanecen con el tiempo.

Conforme a lo mencionado anteriormente, la economía paraguaya se caracteriza por un elevado grado de apertura comercial y bajo nivel de proteccionismo, siendo el comercio la principal fuente de ingresos del país a través de la exportación de materias primas y la triangulación comercial con los países vecinos, Brasil y Argentina. A raíz de esto, la región fronteriza con Brasil históricamente se ha caracterizado por la fuerte influencia económico-comercial del vecino país, principalmente con el Departamento del Alto Paraná (Paraguay), el cual linda con el Estado Brasileño de Paraná (Giménez Béliveau, 2011). Del mismo modo, la región más desarrollada económicamente de Paraguay es la zona Metropolitana compuesta por la capital del país, Asunción, y el Departamento Central. En esta zona se concentra el mayor número de industrias, y además, Asunción es el principal centro comercial del país (DGEEC, 2011; STP, 2017).

De este modo, el objetivo del trabajo es analizar la discriminación salarial por género del sector formal de la zona metropolitana del país y la zona fronteriza con Brasil durante el período 2017 al 2019. Específicamente se pretende verificar el comportamiento y la evolución de la discriminación salarial por género en este período a partir de los datos de la Encuesta Permanente de Hogares (EPH), publicada por la Dirección General de Estadística, Encuestas y Censos del Paraguay.

Respecto a la metodología empleada, la literatura señala que existen diversos métodos para estimar la descomposición salarial y la correspondiente discriminación por género. Entre ellos, se puede citar la metodología de DiNardo, Fortin, \& Lemieux (1996) que consiste en una descomposición semiparamétrica donde el referido autor utiliza las distribuciones salariales en lugar de las medias de las remuneraciones; la de Machado \& Mata (2005) que utiliza regresiones cuantílicas para descomponer la diferencia de salarios; la metodología de Juhn, Murphy, \& Pierce (1991) que permite analizar la desigualdad salarial a lo largo del tiempo; y finalmente, Fortin, Lemieux, \& Firpo (2011), que estima la descomposición de salarios agregados por cada cuantil de ingresos. 
A pesar de la evolución y diversidad de metodologías de descomposición salarial, en este trabajo se optó por emplear la descomposición de Oaxaca-Blinder (1973) combinada con la corrección de Heckman, siendo esta la metodología clásica principal y más utilizada en los trabajos de discriminación salarial por género. En ese sentido, este trabajo aporta a la literatura referente al tema de discriminación salarial por género en Paraguay e innova el uso del método de corrección del sesgo de selección de Heckman, además del estudio regional, específicamente de la zona metropolitana y fronteriza con Brasil. Este último punto es relevante en el sentido de analizar cómo el desarrollo regional podría afectar las desigualdades salariales entre hombres y mujeres.

Los principales resultados señalan que, pese a la disminución de la brecha salarial en el período analizado, aún persisten las desigualdades de ingresos entre hombres y mujeres en el mercado formal de Paraguay en las zonas metropolitana y fronteriza. Parte de la brecha de ingresos se debe a factores no explicados, lo que podría atribuirse a la discriminación contra las mujeres. Así también, se observa que las variables relacionadas con el capital humano contribuyen significativamente a reducir la desigualdad salarial por género.

Con base en los resultados, el trabajo podría dar soporte para la implementación de políticas públicas que garanticen la igualdad salarial entre hombres y mujeres, y así también, dar una mayor preponderancia a la participación femenina en el mercado laboral a través del papel activo del Estado en la promoción de leyes y políticas de protección que respalden el pleno cumplimiento de los derechos de las mujeres. Esto es especialmente importante porque la discriminación por género no solo afecta a la población femenina, sino al propio desarrollo económico del país, al limitar la maximización de la producción por la subutilización de recursos humanos capacitados que son necesarios para incrementar la productividad económica (Kon, 2014).

Finalmente, para cumplir con el objetivo de la investigación, el trabajo está compuesto, además de la introducción, en la sección I, por el referencial teórico donde se describen las teorías del capital humano, y lo referente a la segmentación del mercado laboral por género. En la sección II se describen las evidencias empíricas. Posteriormente, en la sección III, se presenta la metodología, y se explica la metodología econométrica y la caracterización de la muestra, así como el modelo de corrección de Heckman y la descomposición de OaxacaBlinder. Luego, en la sección IV, se describe el mercado laboral de Paraguay con estadísticas oficiales y los resultados, y finalmente en la última sección se desarrolla la conclusión del trabajo. 


\section{LA DISCRIMINACIÓN DE LOS SALARIOS: TEORÍA DEL CAPITAL HU- MANO, TEORÍA DE LA SEGMENTACIÓN DEL MERCADO Y TEORÍAS DE GÉNERO}

La teoría económica clásica establecía que la determinación de los salarios de los individuos estaba sujeta a las fuerzas del mercado conforme a la ley de oferta y demanda de trabajo. De esta forma, los salarios se determinaban por la simple intersección de las curvas de oferta y demanda sin considerar la heterogeneidad de la clase obrera.

Esta fue la idea predominante hasta el advenimiento de la teoría del capital humano desarrollada por diversos autores como Caire \& Becker (1967), Psacharopoulos \& Schultz (1972) y Mincer (1974). En este sentido, la teoría del capital humano considera que la determinación de los salarios se debe a la heterogeneidad de la clase obrera causada por los diferentes niveles de inversión en determinadas variables cognitivas como educación y experiencia que influye en la productividad, empleabilidad y salarios de los individuos (Lima, 1980).

Por consiguiente, Mincer (1974) propuso una ecuación que estima el salario de los individuos dado su nivel educativo y años de experiencia laboral. De este modo, la ecuación minceriana fue la base utilizada por diversos investigadores con la finalidad de estimar la variación media de los ingresos individuales. Así también, el modelo de Oaxaca-Blinder se origina a través de la estimación de la ecuación minceriana (Castillo, 2011; Cirino \& Lima, 2012; Costa, Sousa, \& Guimarães, 2013).

Además, Freire Seoane \& Teijeiro Álvarez (2010) indican que "la ecuación tradicional de Mincer estima por mínimos cuadrados ordinarios (MCO) un modelo semilogarítmico usando como variable dependiente el logaritmo de los ingresos y como variables independientes los años de educación, la experiencia laboral y el cuadrado de ésta”. Esta ecuación se popularizó en múltiples ámbitos debido a su facilidad de aplicación y a su gran capacidad para generar resultados razonables para distintos conjuntos de datos, países, períodos de tiempo, entre otros.

Sin embargo, la teoría del capital humano considera el mercado de trabajo como una unidad homogénea y continua. Por esta razón, surge la teoría de la segmentación del mercado de Stoikov, Doeringer, \& Piore (1972), la cual considera el mercado de trabajo discontinuo y segmentado, siendo una forma alternativa o complementaria de explicar la determinación de los salarios. Mientras la teoría del capital humano busca analizar las capacidades individuales, la teoría de la segmentación del mercado busca analizar los determinantes estructurales para acceder 
a los puestos laborales. Esto significa que las remuneraciones de los individuos dependen de las características del mercado laboral (Biagioni, 2006; Oliveira \& Piccinini, 2011).

En esa perspectiva, el mercado se divide en dos segmentos con características diferenciadas aunque relacionadas con la productividad de los trabajadores, lugar de residencia y origen de los individuos, además de la desigualdad de oportunidades (Biagioni, 2006). En ese sentido, Lima (1980) establece la existencia de un mercado formal que se caracteriza por un empleo estable, salarios acordes a la función desempeñada, elevada productividad, progreso técnico, canales de promoción en las firmas. Por otro lado, un mercado informal está caracterizado por la alta rotación de mano de obra, salarios relativamente bajos, poca productividad, y mínima posibilidad de aumentar los ingresos. Además, en el sector formal, los salarios son negociados entre las partes a través de procedimientos regulados por el Gobierno considerando el costo de vida. Sin embargo, en el sector informal no existen contratos registrados entre las partes, ni cumplimiento de las normas laborales y de seguridad social (Kritz, 2011).

Otra forma de explicar las desigualdades salariales del mercado de trabajo es a través de la discriminación laboral. Esta discriminación consiste en que individuos con mismos atributos productivos perciben salarios diferenciados debido a factores que no están relacionadas con la capacidad productiva. Este tipo de discriminación provoca que las remuneraciones de los hombres sea superior a las de las mujeres, así también que empleados blancos reciban mayores salarios que empleados negros (Cavalieri, 1998; Cirino, 2008; Silva \& Kassouf, 2000).

En este sentido, Ehrenberg \& Smith (2017) alegan que la discriminación por género en el mercado laboral puede adoptar dos formas: en primer lugar, la discriminación salarial, que hace referencia a los empleadores que pagan menos a las mujeres en relación con los hombres a pesar de tener la misma experiencia y ocupar los mismos cargos laborales; en segundo lugar, la discriminación laboral, que se refiere a las mujeres, con la misma educación y potencial productivo, que son derivadas a aquellas actividades laborales menos remuneradas, mientras que los trabajos con mayores retribuciones salariales se destinan a los hombres.

Así también las fuentes generales de discriminación en el mercado de trabajo son las siguientes: primero, el prejuicio personal de los empleadores, compañeros de trabajo y hasta los mismos clientes a quienes no les gusta asociarse con empleados de una determinada raza o sexo. Luego, el prejuicio estadístico caracterizado por el preconcepto hacia un determinado grupo considerando que 
son menos productivos, y finalmente la existencia de fuerzas no competitivas en el mercado laboral.

En cuanto a la discriminación salarial por género, la literatura indica que existen diversas teorías sobre el tema. Una de las teorías pioneras es la teoría de la ventaja comparativa de Becker (1993), que fue creada a partir de sus estudios sobre economía de la familia y economía doméstica dentro de la perspectiva de la economía neoclásica. Según esa teoría, habría una división dentro de las familias sobre uso del tiempo en tareas domésticas no remuneradas y en tareas del mercado de trabajo remuneradas. De este modo, los miembros de la familia desempeñarían las tareas en las que tienen una ventaja comparativa para maximizar su utilidad. Si uno de ellos tiene una ventaja comparativa en el mercado laboral (por ejemplo, profesiones con salario más alto) se especializaría en el mercado laboral. En esa perspectiva, las mujeres tendrían como ventaja comparativa las tareas domésticas debido a su experiencia como madres y amas de casa, contribuyendo a su menor inserción en el mercado de trabajo. De esta forma, la especialización laboral de las parejas sería una forma de maximizar eficiencia y utilidad. Esa fue una de las primeras teorías utilizadas para explicar la división del trabajo entre hombres y mujeres (Melo, Considera, \& Di Sabbato, 2016; Pinheiro, 2016).

Posteriormente Akerlof \& Kranton (2000) desarrollan una nueva teoría para explicar el comportamiento de los individuos y los mercados que permitiría explicar la existencia de la discriminación salarial por género. La llamada "economía de la identidad" (también conocida como teoría de la identidad de género) refuta ideas de la teoría neoclásica al ir en contra de los supuestos de la racionalidad económica, homo economicus y el comportamiento individual guiado solo en las preferencias individuales. Esta nueva teoría expande los conceptos de la economía neoclásica al considerar que la identidad del individuo (como raza, género, clase social y otros factores sociales) tiene un papel preponderante en las decisiones económicas, personales y profesionales, y en el funcionamiento de los mercados. Este enfoque permite la diversidad conductual y muestra la necesidad de incorporar características de los agentes y del ambiente para explicar fenómenos económicos (Anschau \& Marin, 2017; Brites, Marin, \& Almeida, 2019).

Esta teoría altera los supuestos clásicos porque modifica la función de utilidad que se construyen tanto en términos de preferencias como de identidades. Así, las utilidades pueden cambiar según las categorías sociales, de espacio y tiempo. Por tanto, cuando se aplica a la realidad, esta nueva teoría pone las bases para explicar la discriminación salarial de género, así como la desigualdad en la distribución del trabajo doméstico. En ese sentido Akerlof \& Kranton (2000) señalan que a 
partir de ese concepto es posible cambiar el comportamiento de políticas de empleo, organizacionales, y empresariales con la finalidad de reducir esas diferencias.

\section{EVIDENCIAS EMPÍRICAS}

La literatura referente al tema es amplia, en este aspecto existen varios estudios que analizaron la desigualdad salarial por género. Entre ellos se tiene el estudio realizado por Contreras \& Gallegos (2011), en el cual estimaron la diferencia salarial por género de 13 países de América Latina en la década de 1990. Los autores señalan que a pesar de la reducción de la brecha salarial en el período analizado, el salario percibido por los hombres es superior a las mujeres.

Para el caso peruano, Castillo (2011) estimó la desigualdad de ingresos entre hombres y mujeres durante el período 2003 al 2009. Los resultados muestran que la diferencia salarial promedio durante el período de análisis fluctúa entre el 15\% y $25 \%$ a favor de los hombres y la brecha generada por la discriminación es del $8 \%$ al $11 \%$.

Un estudio para los casos de Brasil y México en el 2008 analiza la discriminación salarial y segregación ocupacional contra las mujeres que poseen al menos el nivel de educación superior completo. La investigación señala que la discriminación afecta de forma distinta a los trabajadores más cualificados en relación con los trabajadores menos cualificados (Tatei, 2011). Así también, a través del método de regresión cuantílica, Bartalotti (2007) obtuvo resultados similares, aunque destaca que la discriminación se acentúa en los niveles salariales más elevados.

Por otra parte, Cirino \& Lima (2012) compararon el rendimiento laboral por sexo entre las regiones metropolitanas de Belo Horizonte y Salvador de Brasil. Conforme a lo esperado el rendimiento/hora del trabajo de la región metropolitana de Belo Horizonte es mayor a la de Salvador para ambos sexos. Además, la discriminación racial está presente en ambas regiones, siendo mayor en Salvador.

En esa misma línea, Costa, Sousa, \& Guimarães (2013), utilizando datos de la Pesquisa Nacional por Amostras de Domicílios (PNAD) del año 2012, estimaron el padrón de discriminación del mercado laboral de las regiones metropolitanas de Brasil. Por medio de la estimación de la ecuación minceriana para cada estrato ocupacional, determinaron que en promedio las mujeres y hombres negros reciben menos ingresos que los individuos de color blanco. En ese contexto, el diferencial de ingresos de las regiones metropolitanas es explicado principalmente por la discriminación. 
Para el caso mexicano, Rodríguez-Pérez, Ramos-Lobo \& Castro-Lugo (2017), a través de la combinación de la descomposición de Oaxaca-Blinder con Juhn-Murphy-Pierce (1991, 1993), analizaron la tendencia de la desigualdad salarial antes y después de la crisis de recesión económica durante los períodos 2005, 2009 y 2015 de diferentes segmentos de mercado (público, privado formal e informal). Los resultados mostraron que la diferencia salarial disminuyó tanto en el período anterior a la crisis como en el período posterior en todos los segmentos estudiados.

En otro estudio para México, utilizando la metodología de Fortin, Lemieux y Firpo (2011), Rodríguez Pérez (2020) analizó el diferencial salarial de hombres y mujeres por separado considerando sus características personales y profesionales. Los resultados mostraron que la diferencia salarial aumenta a lo largo de la distribución tanto para el sector informal como para el sector formal, siendo esa diferencia mayor para las mujeres. En el sector público, la diferencia salarial es explicada por características productivas. Al contrario, en el sector privado, la diferencia es explicada por factores no relacionados a la productividad.

En el caso de Paraguay existen varios estudios que analizan la igualdad y equidad de género, así como la disparidad de riquezas entre hombres y mujeres, la desigualdad de ingresos por género en el sector público y privado, la formalización de la economía, además de otros tipos de discriminación vinculados al ámbito político, así como el acceso a servicios de salud y educación (Casalí \& Velásquez, 2016; DGEEC, 2000, 2019; Fernández, 2015; Mongelós, 2015; ONU MUJERES, 2015).

En ese sentido, Serafini (2017), por medio de un análisis descriptivo sobre las desigualdades de ingresos que presentan las mujeres en comparación a los hombres en el mercado laboral, así como las divergencias entre ellas mismas en relación con el ciclo de vida y el área de residencia (urbana-rural) utilizando datos de la Encuesta Permanente de Hogares (EPH) del período 2016, señala que existen disparidades salariales entre ambos géneros a favor de los hombres, y parte de la desigualdad no está explicada por factores estrictamente económicos.

Otros estudios obtuvieron resultados similares usando la base de datos de la EPH 2012 y 2013 respectivamente, en la cual se destaca que la participación femenina en la actividad económica es inferior a los hombres y que estas inequidades persisten en el ámbito laboral paraguayo (PNUD-Paraguay, 2015; PNUD, 2013).

Por otra parte, Báez, Capua, \& Carosini (2019) por medio de una investigación de campo evaluaron la inclusión de medidas de conciliación laboral en las cooperativas de ahorro y crédito de Asunción en el período 2017. Las autoras indican 
que el $100 \%$ de las entidades entrevistadas no disponen de guardería, y solo el $27 \%$ contempla flexibilidad del horario laboral por motivos de maternidad o paternidad, y además, los cargos gerenciales mayoritariamente están ocupados por hombres.

En cuanto al uso del método de estimación de Oaxaca-Blinder, podemos destacar el trabajo realizado por Ortiz-Valverdi (2017), en la cual estima la diferenciación salarial por género en Paraguay usando datos de la Encuesta Permanente de Hogares (EPH) durante el período 2009 al 2015. Los resultados establecen un padrón de discriminación salarial a favor de los hombres en todos los años de estudios que llega al $30 \%$ en promedio.

Así también, Serafini \& Egas (2018) utilizando el método de Oaxaca-Blinder estimaron la brecha salarial entre hombres y mujeres en Paraguay en los años de 1995 y 2015. Los resultados indican que a pesar de la disminución de la brecha salarial, aún persiste la discriminación salarial por género en los años analizados.

\section{METODOLOGÍA}

III.1. Caracterización de la muestra y base de datos

En este trabajo fue utilizada la base de datos de la Encuesta Permanente de Hogares (EPH) de Paraguay de los años 2017 al 2019. Estos datos son publicados anualmente por la Dirección General de Estadísticas, Encuestas y Censos (DGEEC) de Paraguay. El principal objetivo de la EPH es generar indicadores relacionados con el empleo, desempleo, renta y otras características sociales y económicas que permitan conocer la evolución del bienestar de la población paraguaya.

Cabe resaltar que fueron aplicados filtros de selección a la muestra de manera de trabajar con una población homogénea y atender el problema de investigación. En primer lugar, fueron seleccionados los individuos de entre 15 a 65 años de edad con sus respectivos pesos muestrales conforme a lo establecido por la DGEEC y la legislación vigente del mercado laboral paraguayo (Casalí \& Velásquez, 2016). Luego, fue aplicado un filtro a los ingresos mensuales de la categoría de ocupación principal con la finalidad de eliminar los salarios que no representan a la media de la población. Por último, fueron excluidas las categorías ocupacionales de militares, agrícolas, empleador o patrón. 
Así también, fue determinado y caracterizado a los individuos que trabajan en el mercado formal según la categoría de ocupación principal analizada (empleado u obrero privado, empleado u obrero público, trabajador por cuenta propia). De este modo, los individuos que trabajan de forma independiente o por cuenta propia se encuentran en el mercado formal si están inscritos en el Registro Único del Contribuyente (RUC) del Ministerio de Hacienda. Del mismo modo, los individuos que trabajan de forma dependiente o como empleado público o privado están en el sector formal de la economía si aportan a un sistema de jubilación o pensión.

Finalmente, la muestra analizada no incluye todos los departamentos de Paraguay conforme a lo indicado en las secciones anteriores. Entonces este estudio abarca dos regiones específicas, la Región Metropolitana (Asunción y el Departamento Central) y la Zona Fronteriza con Brasil (Departamento de Alto Paraná) con foco en el mercado formal de la economía.

Por tanto, conforme a lo mencionado, el presente artículo utiliza las teorías del capital humano, de segmentación de mercado y de género con la finalidad de estimar el diferencial salarial por género en el mercado de trabajo formal de Paraguay a través del método de Heckman (1979) y la descomposición de OaxacaBlinder (1973).

Las variables seleccionadas basadas en la teoría del Capital Humano se describen en el Cuadro 1. Además, se resalta que el criterio de selección de las variables seleccionadas fue en base a la literatura que concierne al tema.

Cuadro 1. Descripción de las variables

\begin{tabular}{llcc}
\hline Variable & \multicolumn{1}{c}{ Descripción } & Autores & $\begin{array}{c}\text { Señal o efecto } \\
\text { esperado }\end{array}$ \\
\hline Dependiente & & & \\
\hline Lrendaprin & $\begin{array}{l}\text { Variable dependiente de la } \\
\text { ecuación de salarios que } \\
\text { indica el logaritmo natural } \\
\text { del ingreso mensual de } \\
\text { la ocupación principal } \\
\text { declarado. }\end{array}$ & $\begin{array}{c}\text { Contreras \& } \\
\text { Gallegos, 2011; } \\
\text { Costa et al., 2013; }\end{array}$ & - \\
\hline
\end{tabular}




\begin{tabular}{|c|c|c|c|}
\hline Ocupado & $\begin{array}{l}\text { Variable dependiente de } \\
\text { la ecuación de selección. } \\
\text { Dummy que asume valor } \\
1 \text { si el individuo está } \\
\text { ocupado, y } 0 \text { caso contrario. }\end{array}$ & $\begin{array}{c}\text { Monte \& } \\
\text { Gonçalves, } 2006\end{array}$ & - \\
\hline \multicolumn{4}{|l|}{ Independiente } \\
\hline $\begin{array}{l}\text { Año de } \\
\text { estudio }\end{array}$ & $\begin{array}{l}\text { Variable que indica los años } \\
\text { de estudios }\end{array}$ & Castillo, 2011 & Positivo \\
\hline Experiencia & $\begin{array}{l}\text { Variable que indica la } \\
\text { experiencia laboral }\end{array}$ & $\begin{array}{l}\text { Castillo, 2011; } \\
\text { Contreras \& } \\
\text { Gallegos, } 2011\end{array}$ & Positivo \\
\hline Experiencia $^{\wedge} 2$ & $\begin{array}{l}\text { Variable cuadrática que } \\
\text { indica la experiencia al } \\
\text { cuadrado }\end{array}$ & Castillo, 2011 & Negativo \\
\hline Metropole & $\begin{array}{l}\text { Dummy que indica la } \\
\text { Región Metropolitana }\end{array}$ & $\begin{array}{c}\text { Monte \& } \\
\text { Gonçalves, } 2006\end{array}$ & Positivo \\
\hline Frontera & $\begin{array}{l}\text { Dummy que representa el } \\
\text { departamento fronterizo con } \\
\text { Brasil }\end{array}$ & - & Positivo \\
\hline Privado & $\begin{array}{l}\text { Dummy que indica la } \\
\text { categoría de la ocupación } \\
\text { principal, siendo esta: } \\
\text { empleado u obrero privado. }\end{array}$ & $\begin{array}{l}\text { Ortiz-Valverdi, } \\
2017\end{array}$ & Positivo \\
\hline Público & $\begin{array}{l}\text { Dummy que indica la } \\
\text { categoría de la ocupación } \\
\text { principal, siendo esta } \\
\text { empleado u obrero público. }\end{array}$ & $\begin{array}{l}\text { Ortiz-Valverdi, } \\
2017\end{array}$ & Positivo \\
\hline Cuenta propia & $\begin{array}{l}\text { Dummy que indica la } \\
\text { categoría de la ocupación } \\
\text { principal, siendo esta: } \\
\text { trabajador por cuenta propia. }\end{array}$ & $\begin{array}{l}\text { Ortiz-Valverdi, } \\
2017\end{array}$ & Positivo \\
\hline
\end{tabular}




\begin{tabular}{llcc}
\hline Cónyuge & $\begin{array}{l}\text { Dummy que indica si el } \\
\text { individuo forma parte de un } \\
\text { matrimonio. }\end{array}$ & $\begin{array}{c}\text { Monte \& } \\
\text { Gonçalves, 2006 }\end{array}$ & $\begin{array}{c}\text { Positivo para } \\
\text { hombres, } \\
\text { Negativo para } \\
\text { mujeres }\end{array}$ \\
\hline Personaref & $\begin{array}{l}\text { Dummy que indica el jefe } \\
\text { o persona de referencia en } \\
\text { el domicilio, siendo esa la } \\
\text { persona responsable por } \\
\text { el sustento familiar, o sea, } \\
\text { posee mayor ingreso. }\end{array}$ & $\begin{array}{c}\text { Monte \& } \\
\text { Gonçalves, 2006 }\end{array}$ & \\
& & \\
\end{tabular}

Fuente: elaboración propia en base a la literatura

III.2. Modelo econométrico

III.2.1. Corrección de Heckman (1979)

Es común en análisis de ecuaciones de salarios la presencia de sesgo de selección de la muestra. Por tanto, para evitar este problema se utiliza la corrección del sesgo de selección de Heckman (1979). El procedimiento consta de dos ecuaciones, la primera corresponde a la ecuación de selección que indica la probabilidad del individuo de estar empleado, y la segunda consiste en la ecuación de salarios de Mincer modificada (Verbeek, 2007). Por tanto, en este trabajo fueron estimadas las ecuaciones de selección y de ingresos por separado para hombres y mujeres en base a los períodos analizados.

En este sentido, con la finalidad de estimar la ecuación de selección, se utiliza un modelo probit que busca analizar los factores que inciden en la probabilidad de un individuo de estar ocupado, además de estimar la razón inversa de Mills (Cirino \& Lima, 2012; Costa et al., 2013). De este modo, la variable dependiente "ocupado" está en función de las siguientes variables explicativas conforme a la ecuación 1:

$$
\begin{gathered}
\text { ocupado }=\gamma_{0}+\gamma_{1} \text { añosdeestudio }+\gamma_{2} \text { experiencia }+\gamma_{3} \text { experiencia } 2+ \\
\gamma_{4} \text { conyuge }+\gamma_{5} \text { personaref }+\mu_{1}>0 \\
\text { donde: } \mu_{1} N(0, \sigma)
\end{gathered}
$$


Por lo tanto, se espera que la escolaridad aumente la probabilidad del individuo de estar ocupado. Así también, la mayor experiencia eleva las oportunidades laborales pero con rendimientos decrecientes. Por otro lado, si la variable cónyuge es "masculino", debe aumentar la participación del varón en el mercado de trabajo, o de lo contrario disminuir para el caso de las "mujeres" cónyuges. Por último, si el individuo es la persona de referencia del hogar (jefe/a), se espera que esté empleado/a.

Posteriormente, se estima la ecuación de salarios minceriana modificada cuya base es la teoría del capital humano (Mincer, 1974). La variable dependiente de la ecuación consiste en el logaritmo del ingreso de la categoría de ocupación principal y las variables explicativas están representadas en la ecuación 2:

$$
\text { Lrenda } a_{\text {prin }}=\beta_{0}+\beta_{1} \text { añodeestudio }+\beta_{2} \text { experiencia }+\beta_{3} \text { experiencia } 2+
$$

$\beta_{4}$ metropole $+\beta_{5}$ frontera $+\beta_{6}$ publico $+\beta_{7}$ privado $+\beta_{8}$ cuentapropria $+\lambda+\mu_{2}(2)$ donde: $\mu_{2} N(0,1)$ y

$$
\text { correlación }\left(\mu_{1}, \mu_{2}\right)=\rho
$$

Las variables explicativas corresponden a la teoría del capital humano (años de estudio, experiencia y experiencia al cuadrado), además de otras variables dummies como metropole, cuyo valor 1 representa la Región Metropolitana (Asunción y el Departamento Central); frontera, dummy cuyo valor 1 representa el departamento fronterizo con Brasil (Departamentos de Alto Paraná); conjunto de dummies que indican las categorías de la ocupación principal (empleado u obrero público; empleado u obrero privado; trabajador por cuenta propia); $\lambda$, es la razón inversa de Mills o lambda; y $\mu_{2}$, es el término de error.

Los términos de error de las dos ecuaciones $\left(\mu_{1}, \mu_{2}\right)$ son independientes y tienen distribución normal estandarizada. La correlación entre los errores de las dos ecuaciones es igual al parámetro $\rho$ y puede asumir cualquier valor en el intervalo $[-1,1]$. Cuando $\rho \neq 0$, existe sesgo de selectividad.

\section{III.2.2. Descomposición Oaxaca-Blinder}

En la segunda parte del trabajo se buscó descomponer las ecuaciones mincerianas de salarios que fueron estimadas por el procedimiento de Heckman a fin de verificar la existencia de discriminación salarial por género. Para atender tal objetivo se utilizó la metodología creada por Oaxaca y Blinder (1973). En este 
caso, la discriminación está asociada a la brecha salarial entre hombres y mujeres causada por factores no productivos (Costa et al., 2013).

Sinning, Hahn, \& Bauer (2008) postulan que la metodología de Oaxaca-Blinder (1973) proporciona la descomposición de la variable de resultado de los grupos a ser comparados, siendo una parte de la diferencia explicada por las características observables (vector $\mathrm{X}$ de variables explicativas de la regresión) y la otra parte de la diferencia es explicada en los coeficientes (coeficientes $\beta$ de la regresión).

Conforme a lo expuesto, en este estudio la variable de resultado corresponde al logaritmo del ingreso de la ocupación principal. Por su parte, los grupos a ser comparados son: grupo A (compuesto por mujeres) y grupo B (compuesto por hombres). En el vector $X$ de variables explicativas se encuentran las que tienen su origen en la teoría del capital humano (años de estudio, experiencia, experiencia2) y que buscan explicar las características productivas individuales. Como menciona Jann (2008), la descomposición dividirá el diferencial de salario entre hombres y mujeres en una parte, que se explica por diferencias en las características puramente productivas (educación y experiencia) y una parte residual e inexplicable que se utiliza como medida de la discriminación. Para ello inicialmente se estiman dos regresiones de salarios, uno para mujeres y otro para hombres según las siguientes ecuaciones:

$$
\begin{aligned}
& \ln W_{A}=X_{A} \beta_{A}+\mu_{A} \\
& \ln W_{B}=X_{B} \beta_{B}+\mu_{B}
\end{aligned}
$$

Las ecuaciones 3 y 4 están en su forma matricial donde $\ln W$ es el vector del logaritmo natural del ingreso de la ocupación principal individual; $\mathrm{X}$ representa la matriz de variables explicativas; $\beta$ es el vector de los coeficientes incluyendo el intercepto; y $\mu$, vector de término de error. A continuación, se realiza la doble descomposición que conforma la ecuación 5:

$$
\ln W_{A}-\ln W_{B}=\beta_{B}\left(X_{A}-X_{B}\right)+\left(\beta_{A}-\beta_{B}\right) X_{A}
$$

Se tiene que la diferencia del promedio de la renta entre mujeres y hombres, designado por el término ) puede expresarse en función de dos términos. El primer término es $\beta_{B}\left(X_{A}-X_{B}\right)$, que es la parte del diferencial referente a las características productivas o también la diferencia en las características observables. El segundo término $\left(\beta_{A}-\beta_{B}\right) X_{A}$ corresponde al diferencial referente a la disparidad en las características individuales que no están relacionadas a la productividad, este término es la medida de discriminación. 


\section{RESULTADOS Y DISCUSIONES}

IV.1. Estadística descriptiva: mercado laboral de Paraguay

Antes de presentar el análisis econométrico, en esta sección se describen los principales indicadores del mercado laboral de Paraguay según la categoría de ocupación principal a fin de proporcionar un panorama general de los individuos de la muestra en relación con la tasa de participación de la fuerza de trabajo, ocupados y desocupados, y promedio de ingresos mensuales por género, además de la tasa de formalidad del mercado de trabajo, variables de capital humano, así como la jefatura del hogar por sexo.

Primeramente, en la tabla 1 se observa que la muestra está dividida de la siguiente forma: en el año 2017 se encontraban en el sector formal de la economía según la categoría de ocupación principal 3672 varones y 2135 mujeres, luego, en el 2018 habían 2113 varones y 1261 mujeres, y finalmente, en el año 2019 el mercado estaba conformado por 2179 hombres y 1301 mujeres, lo que indica una mayor cantidad de empleados varones en esa categoría. Además, en relación con las variables del capital humano, las mujeres en promedio poseen una mayor escolaridad que los varones, y por el contrario, los hombres presentan mayor experiencia laboral que las mujeres.

Tabla 1. Descripción de la muestra

\begin{tabular}{|c|c|c|c|c|c|c|}
\hline \multirow{2}{*}{ Medias } & \multicolumn{2}{|c|}{2017} & \multicolumn{2}{|c|}{2018} & \multicolumn{2}{|c|}{2019} \\
\hline & Hombres & Mujeres & Hombres & Mujeres & Hombres & Mujeres \\
\hline N. ${ }^{\circ}$ obs. & 3672 & 2135 & 2113 & 1261 & 2179 & 1301 \\
\hline $\begin{array}{l}\text { Años de } \\
\text { Estudios }\end{array}$ & 11 & 13.36 & 11.24 & 13.43 & 11.38 & 13.59 \\
\hline $\begin{array}{c}\text { Años de } \\
\text { experiencia }\end{array}$ & 18.50 & 15.86 & 18.22 & 16.36 & 18.62 & 16.81 \\
\hline
\end{tabular}

Fuente: elaboración propia con datos de la EPH 2017, 2018 y 2019. 
Seguidamente, se grafica la tasa de la fuerza de trabajo en porcentaje, por sexo y por trimestres para el período 2018-2019, según datos publicados por la DGEEC. En el gráfico se puede observar que la tasa de la fuerza de trabajo masculina es superior a la tasa de la fuerza de trabajo femenina en todos los trimestres analizados, aunque el incremento interanual en la fuerza laboral a nivel país se dio principalmente en la población femenina, que pasó de $58.4 \%$ a $61.3 \%$, entre el primer trimestre del 2018 y el correspondiente del 2019. Así también, la tasa de la fuerza laboral total aumentó en $1.7 \%$ entre el cuarto trimestre del 2018 y el primer trimestre del 2019.

Gráfico 1. Tasa de la fuerza de trabajo (\%) por sexo, según trimestre y año. Años 2018 y 2019

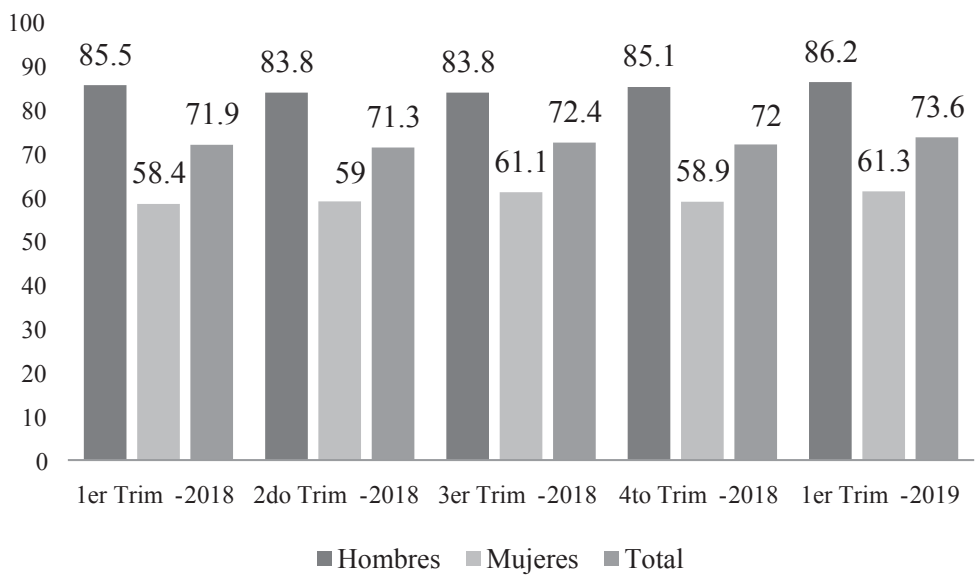

Fuente: DGEEC. Encuesta Permanente de Hogares Continua 2018-2019.

Considera todas las categorías ocupacionales a nivel país del mercado formal e informal. No incluye los departamentos de Boquerón y Alto Paraguay.

En el gráfico 2 se muestra la tasa de ocupados por sexo, según trimestres y años, para el periodo 2018 y 2019. Se observa que la tasa de ocupación a nivel país fue de $68.5 \%$ para el primer trimestre del 2019 , cifra superior a la registrada en el mismo trimestre del año 2018 (66.6\%). Las tasas de ocupación para el primer trimestre de 2019, tanto de los hombres (81.5\%) como de las mujeres $(55.8 \%)$, registraron incrementos interanuales de $1 \%$ y $3 \%$ respectivamente, en comparación al mismo trimestre del año anterior. 
Gráfico 2. Tasa de ocupados (\%) por sexo según trimestre y año. Años 2018 y 2019

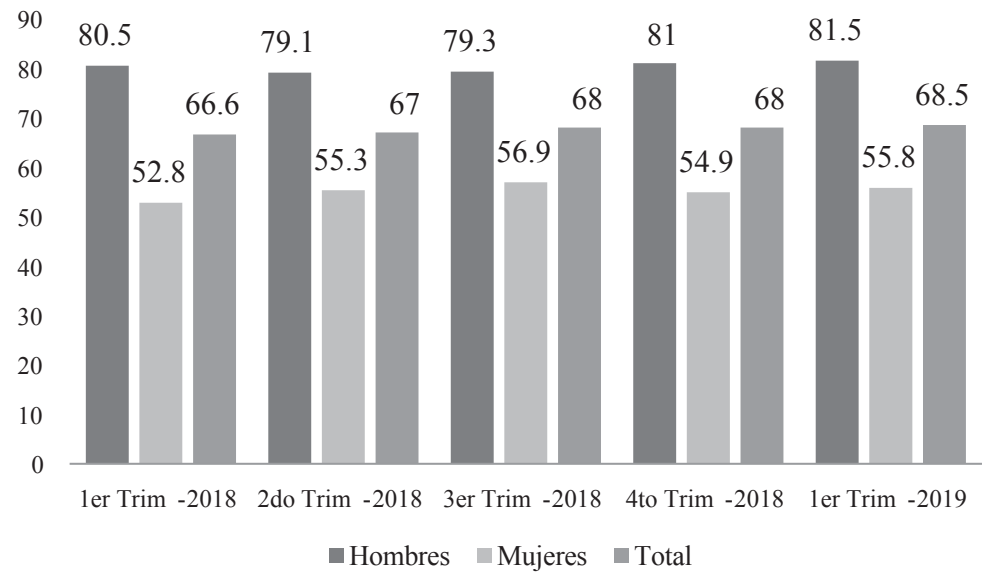

Fuente: DGEEC. Encuesta Permanente de Hogares Continua 2018-2019.

Considera todas las categorías ocupacionales a nivel país del mercado formal e informal.

No incluye los departamentos de Boquerón y Alto Paraguay. Gráfico 3. Tasa de desocupación (Desempleo Abierto) (\%) por sexo según trimestre y año. Años 2018 y 2019

Gráfico 3. Tasa de desocupación (Desempleo Abierto) (\%) por sexo según trimestre y año. Años 2018 y 2019

12

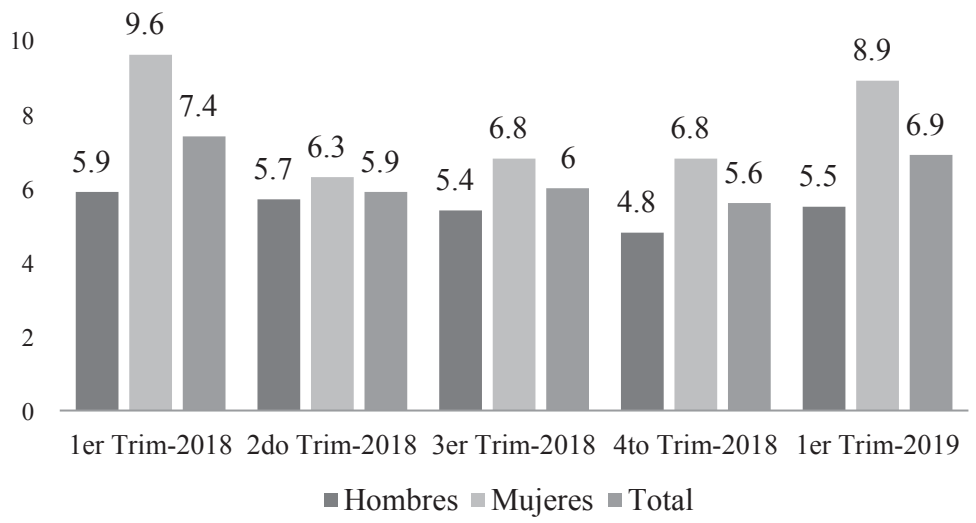

Fuente: DGEEC. Encuesta Permanente de Hogares Continua 2018-2019.

Considera todas las categorías ocupacionales a nivel país del mercado formal e informal. No incluye los departamentos de Boquerón y Alto Paraguay. 
En el gráfico 3 se muestra la tasa de desocupación por sexo, según trimestre y año, para los períodos 2018 y 2019. Se observa que, a nivel nacional, la tasa de desocupación para el primer trimestre del 2019 fue de $6.9 \%$, lo que implica una leve disminución de $0.5 \%$, respecto del mismo trimestre del año 2018, que fue de $7.4 \%$. Este comportamiento se ve reflejado en la disminución de la tasa de desocupación femenina de $9.6 \%$ a $8.9 \%$ y masculina de $5.9 \%$ a $5.5 \%$, comparando los primeros trimestres de cada periodo mencionado.

Por otra parte, en la tabla 2 se presenta el ingreso promedio mensual total y por sexo de la principal categoría ocupacional independientemente de otras variables. En este caso, se ha considerado los ingresos mensuales de las personas en la ocupación principal ya que contempla más del $90 \%$ de todos los ingresos de los individuos (PNUD, 2013).

En promedio el ingreso de la mujer es inferior al del varón en todos los años analizados, de este modo en el 2017 y 2018 las mujeres percibían solamente el 86\% del salario del varón, y en 2019 la brecha salarial aumentó, de esta manera el ingreso promedio de las mujeres fue de $16 \%$ menos en relación con los hombres. Sin embargo, a partir del análisis del promedio de la renta no es posible afirmar la existencia de discriminación salarial, pues no es un análisis controlado y no considera el modelo econométrico. Según las categorías ocupacionales, se observa que la categoría por cuenta propia presenta mayores divergencias salariales entre ambos sexos. Por el contrario, la categoría de empleado obrero privado es el que presenta mayor convergencia salarial (96\%) entre los individuos en los años analizados. Por otro lado, pese a la disminución de las brechas salariales en el sector público en los últimos años aún persisten importantes diferencias de ingresos entre ambos géneros.

Tabla 2. Promedio de ingresos mensuales (en guaraníes) por sexo según categoría en ocupación principal, período 2017-2019

\begin{tabular}{|c|c|c|c|c|}
\hline \multicolumn{5}{|c|}{ Año 2017} \\
\hline Categoría en Ocupación Principal & Hombres & Mujeres & Total & $\mathrm{M} / \mathrm{H}(\%)$ \\
\hline Empleado / obrero público & 4200901 & 3294306 & 3747604 & $78 \%$ \\
\hline Empleado / obrero privado & 2285588 & 2187195 & 2236391 & $96 \%$ \\
\hline Empleador o patrón & 5305625 & 5214018 & 5259821 & $98 \%$ \\
\hline Trabajador por cuenta propia & 1865866 & 1282880 & 1574373 & $69 \%$ \\
\hline
\end{tabular}




\begin{tabular}{|c|c|c|c|c|}
\hline Empleado doméstico & 1653756 & 1187135 & 1420445 & $72 \%$ \\
\hline Total & 3062347 & 2633107 & 2847727 & $86 \%$ \\
\hline \multicolumn{5}{|c|}{ Año 2018} \\
\hline Categoría en Ocupación Principal & Hombres & Mujeres & Total & $\mathrm{M} / \mathrm{H}(\%)$ \\
\hline Empleado / obrero público & 4499032 & 3663445 & 4081238 & $81 \%$ \\
\hline Empleado / obrero privado & 2380329 & 2288594 & 2334461 & $96 \%$ \\
\hline Empleador o patrón & 5853008 & 5499408 & 5676208 & $94 \%$ \\
\hline Trabajador por cuenta propia & 1838793 & 1264934 & 1551864 & $69 \%$ \\
\hline Empleado doméstico & 1594640 & 1250696 & 1422668 & $78 \%$ \\
\hline Total & 3233160 & 2793415 & 3013288 & $86 \%$ \\
\hline \multicolumn{5}{|c|}{ Año 2019} \\
\hline Categoría en Ocupación Principal & Hombres & Mujeres & Total & $\mathrm{M} / \mathrm{H}(\%)$ \\
\hline Empleado / obrero público & 4316561 & 3703719 & 4010140 & $86 \%$ \\
\hline Empleado / obrero privado & 2458506 & 2366982 & 2412744 & $96 \%$ \\
\hline Empleador o patrón & 5190479 & 4085492 & 4637986 & $79 \%$ \\
\hline Trabajador por cuenta propia & 1738949 & 1338913 & 1538931 & $77 \%$ \\
\hline Empleado doméstico & 1586927 & 1289976 & 1438452 & $81 \%$ \\
\hline Total & 3058284 & 2557017 & 2807651 & $84 \%$ \\
\hline
\end{tabular}

Notas: 1) Se registra la categoría en la ocupación principal en los últimos 7 días; 2) Ingresos mensuales son los ingresos laborales por la actividad principal con un ingreso inferior a Gs. 60000000 mensuales por persona en todos los casos y se excluyen los ingresos igual a cero. Fuente: elaboración propia a partir de la EPH 2017-2019.

A continuación, en la tabla 3 se presentan los indicadores de empleo formal de la categoría de la ocupación principal por área de residencia y sexo. En general se considera que un individuo se encuentra en el sector formal de la economía si está registrado en el Registro único del Contribuyente (RUC) en el caso de los trabajadores independientes, o si aporta a un sistema de jubilación o pensión en el caso de los dependientes. En esta perspectiva, se observa que en el año 2017 el $59 \%$ de los individuos desempeñaban sus actividades laborales en un estableci- 
miento económico con RUC y solo el 28\% realizó aporte jubilatorio. Estas cifras aumentaron en los siguientes años (2018-2019), a 62\% y 29\% respectivamente.

Tabla 3. Indicadores de empleo formal para la población ocupada en la categoría de ocupación principal por área de residencia y sexo, período 2017-2019.

\begin{tabular}{|c|c|c|c|c|c|c|}
\hline \multicolumn{7}{|c|}{ Año 2017} \\
\hline \multirow{2}{*}{ Indicadores } & \multicolumn{3}{|c|}{ Urbana } & \multicolumn{3}{|c|}{ Rural } \\
\hline & Total & Hombres & Mujeres & Total & Hombres & Mujeres \\
\hline Tiene RUC & $59 \%$ & $62 \%$ & $56 \%$ & $35 \%$ & $40 \%$ & $30 \%$ \\
\hline Aporta jubilación & $28 \%$ & $28 \%$ & $28 \%$ & $17 \%$ & $18 \%$ & $15 \%$ \\
\hline \multicolumn{7}{|c|}{ Año 2018} \\
\hline \multirow{2}{*}{ Indicadores } & \multicolumn{3}{|c|}{ Urbana } & \multicolumn{3}{|c|}{ Rural } \\
\hline & Total & Hombres & Mujeres & Total & Hombres & Mujeres \\
\hline Tiene RUC & $62 \%$ & $65 \%$ & $59 \%$ & $40 \%$ & $44 \%$ & $35 \%$ \\
\hline Aporta jubilación & $29 \%$ & $29 \%$ & $30 \%$ & $17 \%$ & $18 \%$ & $17 \%$ \\
\hline \multicolumn{7}{|c|}{ Año 2019} \\
\hline \multirow{2}{*}{ Indicadores } & \multicolumn{3}{|c|}{ Urbana } & \multicolumn{3}{|c|}{ Rural } \\
\hline & Total & Hombres & Mujeres & Total & Hombres & Mujeres \\
\hline Tiene RUC & $62 \%$ & $65 \%$ & $59 \%$ & $30 \%$ & $37 \%$ & $24 \%$ \\
\hline Aporta jubilación & $29 \%$ & $29 \%$ & $28 \%$ & $11 \%$ & $12 \%$ & $10 \%$ \\
\hline
\end{tabular}

Fuente: Elaboración propia a partir de la EPH 2017-2019.

En cuanto a la informalidad del mercado laboral en relación con el género y el área de residencia, se observa, en la zona urbana y rural, que las mujeres presentan mayores tasas de informalidad, y este problema se agudiza en las zonas rurales tanto para hombres y mujeres. Un hecho que se destaca es que las tasas de informalidad aumentaron en el año 2019 en la zona rural.

La siguiente tabla muestra los ingresos mensuales promedio de la categoría de ocupación principal de los jefes de hogares por sexo y área de residencia. 
Tabla 4. Ingresos mensuales promedio (en guaraníes) de los/as jefes/as por área de residencia, período 2017-2019

\begin{tabular}{ccccccc}
\hline \multirow{2}{*}{ Año } & \multicolumn{3}{c}{ Urbana } & \multicolumn{3}{c}{ Rural } \\
\cline { 2 - 7 } & Hombres & Mujeres & M/H (\%) & Hombres & Mujeres & M/H (\%) \\
\hline 2017 & 3401489 & 2002032 & $59 \%$ & 2336122 & 1457009 & $62 \%$ \\
2018 & 3633738 & 2079369 & $57 \%$ & 2417161 & 1383275 & $57 \%$ \\
2019 & 3454048 & 2223912 & $64 \%$ & 2411271 & 1509559 & $63 \%$ \\
\hline
\end{tabular}

Fuente: Elaboración propia a partir de la EPH 2017-2019.

En el año 2018 las brechas de ingresos persisten tanto en la zona urbana y rural. Los hogares cuya jefatura del hogar es femenina perciben solamente el 57\% de los ingresos de los hogares con jefatura masculina. Por último, pese a la disminución de las brechas salariales en el año 2019, las mujeres jefas de familia reciben $36 \%$ y $37 \%$ menos que los jefes de hogares varones en la zona urbana y rural.

\section{IV.2. Análisis econométrico}

Esta sección muestra el análisis econométrico del trabajo presentando, primeramente los resultados de la corrección de Heckman y posteriormente la descomposición de Oaxaca-Blinder. El procedimiento de corrección del sesgo de selección de Heckman en dos etapas tiene como etapa inicial la estimación de la ecuación de selección para hombres y mujeres, siendo esa un probit que muestra las probabilidades del individuo de estar empleado. Los resultados encontrados se encuentran en la tabla 5.

Inicialmente en la tabla 5 se observa el alto poder explicativo de las variables utilizadas como regresores, ya que prácticamente todas fueron estadísticamente significativas al $1 \%$ tanto en la ecuación de selección de hombres y mujeres en todos los años analizados (con excepción de las variables experiencia e experiencia al cuadrado para el caso de los hombres en 2019). De este modo, las variables relativas al capital humano (años de estudio y experiencia) aumentan la probabilidad de hombres y mujeres de estar empleados conforme indica la literatura (Schultz, 1961; Becker, 1964; Mincer, 1974). 
DISCRIMINACIÓN SALARIAL POR GÉNERO EN EL MERCADO DE TRABAJO DEL PARAGUAY...

Tabla 5. Ecuación de selección de hombres y mujeres. Período 2017-2019

\begin{tabular}{|c|c|c|c|c|c|c|c|}
\hline \multicolumn{5}{|c|}{$\begin{array}{l}\text { Probit: Ocupado 1; no } \\
\text { ocupado } 0\end{array}$} & \multicolumn{3}{|c|}{$\begin{array}{l}\text { Probit: Ocupado 1; no } \\
\text { ocupado } 0\end{array}$} \\
\hline \multicolumn{5}{|c|}{$\begin{array}{l}\text { Ecuación de selección de } \\
\text { hombres }\end{array}$} & \multicolumn{3}{|c|}{$\begin{array}{c}\text { Ecuación de selección de } \\
\text { mujeres }\end{array}$} \\
\hline Variables & 2017 & 2018 & 2019 & Variables & 2017 & 2018 & 2019 \\
\hline Constante & $\begin{array}{c}-0.4753^{*} \\
(.0625)\end{array}$ & $\begin{array}{l}-0.2442 * \\
(0.0876)\end{array}$ & $\begin{array}{l}-0.2436^{*} \\
(0.0908)\end{array}$ & Constante & $\begin{array}{l}-1.010^{*} \\
(0.0394)\end{array}$ & $\begin{array}{r}-0.8827^{*} \\
(0.0495)\end{array}$ & $\begin{array}{l}-0.8798 * \\
(0.0544)\end{array}$ \\
\hline Años de estudio & $\begin{array}{l}0.0457^{*} \\
(0.0036)\end{array}$ & $\begin{array}{l}0.0500 * \\
(0.0059)\end{array}$ & $\begin{array}{l}0.0491 * \\
(0.0067)\end{array}$ & $\begin{array}{l}\text { Años de } \\
\text { estudio }\end{array}$ & $\begin{array}{l}0.0742 * \\
(0.0026)\end{array}$ & $\begin{array}{l}0.0727 * \\
(0.0036)\end{array}$ & $\begin{array}{l}0.0650^{*} \\
(0.0035)\end{array}$ \\
\hline Experiencia & $\begin{array}{l}0.0824^{*} \\
(0.0072)\end{array}$ & $\begin{array}{l}0.0413 * \\
(0.0039)\end{array}$ & $\begin{array}{l}0.0023 \mathrm{NS} \\
(0.0057)\end{array}$ & Experiencia & $\begin{array}{l}0.0727^{*} \\
(0.0022)\end{array}$ & $\begin{array}{l}0.0543 * \\
(0.0027)\end{array}$ & $\begin{array}{l}0.0704 * \\
(0.0032)\end{array}$ \\
\hline
\end{tabular}

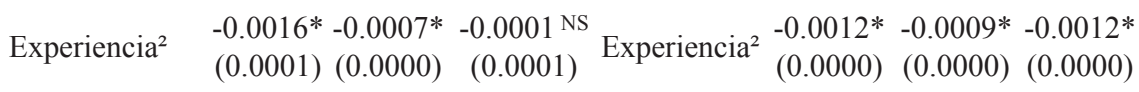

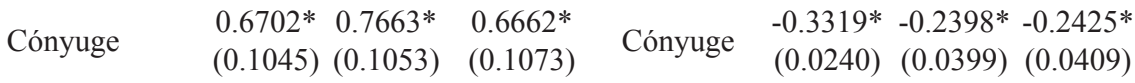

Persona de $0.6702 * 0.7023 * * 0.5953 *$ Persona de $0.4456 * 0.5287 * 0.4308 *$ $\begin{array}{llllllll}\text { referencia } & (0658) & (0.0641) & (0.0662) & \text { referencia } & (0.0423) & (0.0416) & (0.0419)\end{array}$

Fuente: elaboración propia con datos de la EPH 2017, 2018 e 2019.

Nota: significativo $* 1 \%, * * 5 \%, * * * 10 \%$, NS no significativo. 
Según Pereira \& Oliveira (2016), la variable experiencia al cuadrado por su naturaleza cuadrática experimenta un comportamiento peculiar, pues el signo negativo indica que la experiencia se va depreciando con el tiempo, o sea, habrá una menor probabilidad de que el individuo esté ocupado conforme vaya envejeciendo confirmando la hipótesis de depreciación del capital humano.

En relación con la variable jefe o persona de referencia (individuo responsable del sustento familiar y que posee mayor ingreso), la probabilidad de estar empleado aumenta en todos los años tanto para hombres como mujeres pero siendo ligeramente superior para los hombres. En este sentido, la teoría indica que los individuos del sustento familiar poseen mayores probabilidades de empleabilidad.

Además la variable conyugue también aumenta la probabilidad de empleabilidad de los hombres. Al contrario, para las mujeres la variable presentó señal negativa indicando que disminuye su probabilidad de participar en el mercado de trabajo. En efecto, una posible justificación para tal resultado sería el hecho de que las mujeres casadas asuman la responsabilidad de realizar las tareas domésticas y se encarguen del cuidado de los hijos disminuyendo su probabilidad de estar empleadas (Duflo, 2011). Este resultado también puede ser explicado por la teoría de la ventaja comparativa de Becker (1993) sobre la división del trabajo en el hogar que históricamente lo han desempeñado las mujeres.

Por otro lado, evaluando separadamente la ecuación de selección de hombres y mujeres, a lo largo de los años de estudio, se puede constatar que los parámetros de la ecuación de selección no presentan diferencias significativas, lo mismo puede ser observado para el nivel de significancia estadística. La segunda etapa del proceso de corrección de Heckman consiste en estimar la ecuación de salarios corregida del sesgo de selección. A partir de los coeficientes de la ecuación de selección se calcula la razón de Mills siendo ese el término de corrección del sesgo de selectividad. Conforme a la tabla 6, la razón de Mills fue significativa al $1 \%$ tanto en la ecuación de hombres como mujeres durante el período analizado. Lo que significa la necesidad de corregir la presencia de selectividad a través del procedimiento de Heckman, y para este proceso es incluida la razón de Mills como variable explicativa en la estimación de los salarios. Según Pereira \& Oliveira (2016), citado en Kassouf (1994) y Resende e Wyllie (2006), la señal negativa de la razón de Mills señala que los factores no medidos que aumentan la probabilidad de empleabilidad reducen los salarios. 
Por consiguiente, las variables explicativas del salario fueron significativas en la ecuación de rendimiento femenino en todos los casos. Al contrario, para el caso de los hombres la variable privada no fue significativa en todos los períodos, además la variable experiencia y experiencia al cuadrado solamente fueron significativas en algunos casos. A pesar de eso, las variables relacionadas con el capital humano (experiencia y años de estudio) presentaron las señales esperadas según la literatura, o sea, mayor capital humano está relacionada a salarios superiores.

Por otro lado, la variable Metropole indica que si el individuo reside en la zona metropolitana contribuye a obtener mayores ingresos tanto para hombres como mujeres en todos los años. En general, la zona metropolitana se caracteriza por un mayor dinamismo económico y concentración del PIB a nivel nacional (Cirino \& Lima, 2012). Así también, residir en la frontera Brasil-Paraguay contribuye a alcanzar salarios más elevados durante el período analizado. Esto puede ser justificado por el hecho de que la economía del Paraguay está estrechamente vinculada a la de Brasil en relación con el turismo de compra en la zona fronteriza (Carrón \& Silva, 2007).

En cuanto a los resultados de las categorías ocupacionales, estos muestranque la variable privado (trabajadores del sector privado) apenas fue significativopara las mujeres. Esto significa que el salario de las mujeres aumenta si ella está trabajando en el sector privado.

Del mismo modo la variable público (trabajadores del sector público) muestra una señal positiva para las mujeres indicando que contribuye a aumentar los salarios. Por otra parte, en relación con los hombres, la variable público presenta señal negativa, lo que significa que trabajar en el sector privado puede incidir negativamente sobre su salario.

Además, para la ecuación de ingresos también se puede constatar que los parámetros no se alteran de forma significativa, lo mismo puede ser observado para el nivel de significancia a lo largo del tiempo para hombres y mujeres.

La etapa final del trabajo busca verificar la existencia de discriminación salarial por género en el mercado de trabajo del sector formal del Paraguay. Para ello se hace necesario realizar el análisis controlado del diferencial de salarios a través de la Descomposición de Oaxaca-Blinder. Los resultados se encuentran en la tabla 7 respectivamente. 


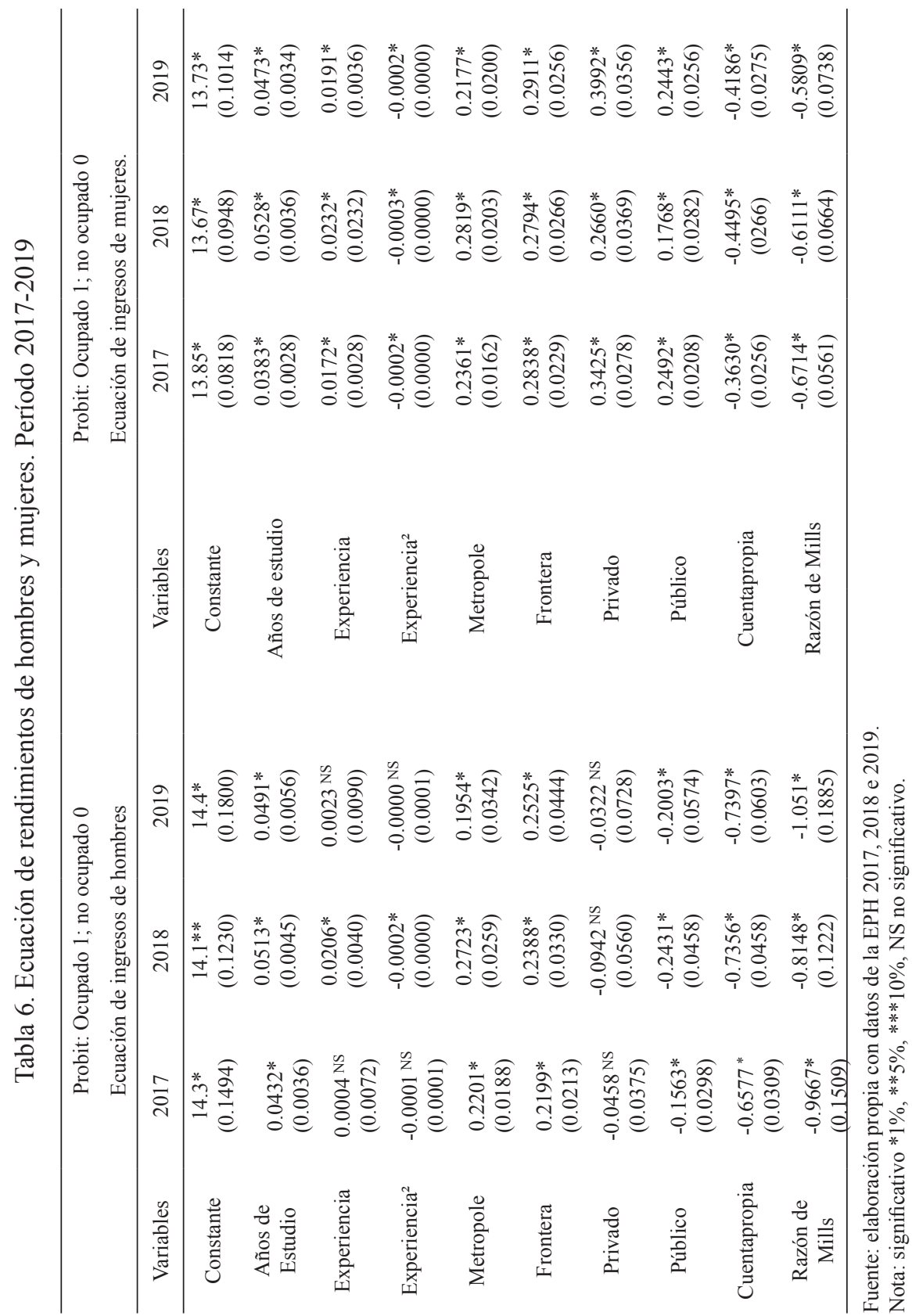


Se observa que la diferencia salarial entre hombres y mujeres es estadísticamente significativa al 1\% y $5 \%$ en el período analizado. Así también, considerando que la variable dependiente corresponde al logaritmo de la renta de la ocupación principal, los resultados son los siguientes: en el año 2017 el promedio logarítmico de la renta de los hombres es 14.69 y de las mujeres es 14.61, entonces la brecha salarial por género asciende a $8.79 \%$. En ese sentido, aplicando antilog para verificar la diferencia en términos monetarios se tiene que el promedio geométrico de la renta mensual para los hombres es de $\mathbb{G} 2420432$ y para las mujeres es de G 2225884 con una diferencia salarial de $8.74 \%$ a favor de los hombres.

Del mismo modo, en el año 2018 se observa una diferencia salarial del $5.46 \%$ a favor de los individuos de sexo masculino. Luego, en el año 2019 la desigualdad salarial se reduce ligeramente, aunque nuevamente las mujeres se encuentran en desventaja. En efecto, a lo largo de la trayectoria de tiempo analizada se observa una reducción de la diferencia en las remuneraciones entre ambos sexos. Resultado similar fue hallado por Ortiz-Valverdi (2017) en la cual indica decrecimiento de la desigualdad salarial por género entre el período de 2009 y 2015.

Conforme a los resultados obtenidos, parte de la desigualdad de ingresos entre hombres y mujeres se debe a factores estrechamente ligados a la productividad de los individuos. En general, las características productivas ayudan a reducir la desigualdad salarial entre ambos sexos durante el período de 2017 al 2019, principalmente los años de escolaridad. Esto significa que las mujeres deberían realizar una mayor inversión en educación en relación con los hombres para igualar los salarios. Las estadísticas descriptivas corroboran estos resultados, indicando que las mujeres poseen mayores años de estudios que los hombres. Pese a la mayor escolaridad, la experiencia aún es un factor clave de la desigualdad salarial por género. Además, es importante resaltar que la variable frontera no afectó el diferencial salarial de 2018 para adelante.

No obstante, la parte del componente de factores no explicados que es atribuida a la discriminación salarial por género fue de $18.35 \%, 17.64 \%$ y $17.02 \%$ durante el período de análisis. De este modo se puede afirmar que una de las causas de la brecha salarial por género en Paraguay se debe a la discriminación en el mercado laboral. En este sentido, pese que las mujeres invierten más en características productivas no es suficiente para compensar los salarios percibidos por los hombres. En ese sentido, Duflo (2011) indica que las diferencias en la participación laboral y los salarios persisten, particularmente en los puestos de mayor jerarquía, lo que se debe a los prejuicios, así como a las diferentes actitudes culturales hacia las mujeres. 
Tabla 7. Descomposición de Oxaca-Blinder. Período 2017-2019

\begin{tabular}{|c|c|c|c|}
\hline Diferencial & 2017 & 2018 & 2019 \\
\hline Hombres & $14.69^{*}$ & $14.73 *$ & $14.77 *$ \\
\hline Mujeres & $14.61 *$ & $14.67 *$ & $14.72 *$ \\
\hline Brecha salarial & $0.0879 *$ & $0.0546 * *$ & $0.0513 * *$ \\
\hline \multicolumn{4}{|c|}{ Descomposición } \\
\hline Componente Explicativo & $-0.9974 *$ & $-0.1217^{*}$ & $-0.1188^{*}$ \\
\hline Añoestudio & $-0.1036^{*}$ & $-0.1045^{*}$ & $-0.0894 *$ \\
\hline Experiencia & $0.0300^{*}$ & $0.0223 *$ & $0.0145^{* *}$ \\
\hline Metropole & $-0.0035 * *$ & $-0.0060^{* *}$ & $-0.0033 * *$ \\
\hline Frontera & $0.0035^{* *}$ & $-0.0006^{\mathrm{NS}}$ & $0.0004 \mathrm{NS}$ \\
\hline Cate & $-0.0261 *$ & $-0.0326^{*}$ & $-0.0411^{*}$ \\
\hline Componente Inexplicado & $0.1835^{*}$ & $0.1764 *$ & $0.1702 *$ \\
\hline Añoestudio & $-0.0195^{\mathrm{NS}}$ & $-0.1794 * *$ & $-0.1568 * *$ \\
\hline Experiencia & $0.0423 \mathrm{NS}$ & $0.0557 \mathrm{NS}$ & $0.0775 * *$ \\
\hline Metropole & $-0.0354 *$ & $-0.0255 \mathrm{NS}$ & $-0.0554 *$ \\
\hline Frontera & $-0.0165^{*}$ & $-0.0092 \mathrm{NS}$ & $-0.0131 \mathrm{NS}$ \\
\hline Cate & $0.0176^{\mathrm{NS}}$ & $0.0244 \mathrm{NS}$ & $-0.1368 * *$ \\
\hline Constante & $0.1950 * *$ & $0.3105 * *$ & $0.4581 *$ \\
\hline
\end{tabular}

Fuente: Elaboración propia con datos de la EPH 2017, 2018 e 2019.

Nota: significativo $* 1 \%, * * 5 \%, * * * 10 \%$, NS no significativo.

Se observa que dentro del componente explicado las variables años de estudio, metropole y cate (categoría de ocupación público, privado y cuenta propia) están contribuyendo a reducir la diferencia salarial entre los grupos. En efecto, la variable que explica con mayor fuerza la diferencia salarial en el período analizado es la escolaridad (año de estudios). En ese sentido, Contreras \& Gallegos (2011) observaron que la educación fue el principal factor para explicar la diferencia salarial por género en América Latina. 
Por otra parte, la variable Metropole también contribuye a reducir las desigualdades para todos los años y esto puede ser justificado por el hecho de que cuanto más pujante y diversificada la economía, menor tiende a ser la discriminación salarial por género. Por el contrario, la variable experiencia está contribuyendo a elevar la desigualdad salarial entre los grupos, sin embargo, presenta una tendencia decreciente a lo largo del tiempo. En efecto, el hecho de que la experiencia esté contribuyendo a explicar las desigualdades puede ser debido a que en la muestra analizada los varones presentan en promedio mayor experiencia laboral que mujeres. Así también, conforme a lo estipulado en la literatura referente al ciclo de vida, las mujeres tienden a ausentarse del mercado de trabajo con más frecuencia que los hombres (para el cuidado de la familia) y cuando se reintegran al mercado laboral sus ingresos sufren una reducción (Cirino, 2008 citado en Mincer \& Polachek 1974 ).

Al final del trabajo se observó que los resultados son compatibles con la economía de la identidad y la teoría de Akerlof \& Kranton (2000) que afirma que la identidad del individuo (como género) tiene un papel preponderante para el funcionamiento de los mercados, incluso para el mercado laboral y la determinación de los salarios. Así también, la discriminación salarial por género presentó un comportamiento decreciente en el período de 2017 a 2019. Resultado similar fue encontrado para Contreras \& Gallegos (2011) para el caso de América Latina en el que se observó una reducción en la diferencia salarial de género durante la década de los 90. Además, en un estudio más reciente Rodríguez-Pérez et al. (2017) llegaron al mismo resultado para el caso de México en que se observó que la principal fuente de la desigualdad salarial era el componente no explicado, pero esa desigualdad presentó comportamiento decreciente en el período de 2005, 2009 y 2015.

\section{CONCLUSIÓN}

El presente artículo utiliza datos de la EPH 2017, 2018 y 2019 con el fin de analizar la desigualdad salarial por género en el mercado laboral del sector formal de la economía paraguaya y su evolución en los últimos años teniendo como foco la zona metropolitana y la región fronteriza con Brasil. En este sentido, para cuantificar la diferencia de ingresos entre hombres y mujeres, primeramente fue estimada la ecuación minceriana (1974) para luego utilizar el método de descomposición de Oaxaca-Blinder (1973) que nos proporciona la medida de la diferencia salarial explicada por la discriminación. Además, en este proceso se aplicó el método de corrección del sesgo de selección muestral de (Heckman, 1979). 
Los resultados indican que conforme a lo esperado, el salario de los hombres es superior a las mujeres aunque con una tendencia decreciente durante el período analizado. En consecuencia la discriminación por género en promedio es responsable del $17.67 \%$ de las diferencias en la remuneración entre ambos grupos. Así también, en relación con la zona de residencia del individuo, la zona metropolitana ayuda a disminuir las desigualdades de ingresos entre hombre y mujeres, en cambio, la zona fronteriza acrecienta las diferencias salariales. Por otro lado, el procedimiento de Heckman apuntó la necesidad de corregir la ecuación de salarios con el fin de obtener estimativas consistentes de los parámetros debido a la existencia de sesgo de selección muestral.

Así también, los resultados de este trabajo siguen la línea de la economía de la identidad y la teoría de Akerlof \& Kranton (2000) que señalan que la identidad del individuo como el género ejerce una función determinante para el funcionamiento de los mercados. Del mismo modo, sigue la línea de la teoría del capital humano de Schultz (1961), Becker (1964) y Mincer (1974) que afirman que la inversión en capital humano aumenta la probabilidad de los individuos a estar empleados, además de contribuir a la reducción de las desigualdades salariales.

A pesar de que la evolución de la discriminación señala una tendencia decreciente a lo largo de los años, todavía está presente en el mercado laboral paraguayo. En ese sentido, Duflo (2011) afirma que es necesario aplicar políticas públicas para alcanzar la igualdad y equidad de género. Por lo tanto, es necesario implementar políticas que garanticen la igualdad salarial entre hombres y mujeres, así como leyes que protejan a la mujer contra todo tipo de discriminación y que fomenten su pleno desarrollo personal y profesional. En ese sentido, Kon (2014) menciona la necesidad de la articulación entre políticas de empleo y políticas de educación, formación profesional, cuidado infantil, salud, protección social. Además de políticas de flexibilidad en la jornada laboral, permiso por maternidad, guarderías para el cuidado de los/as niños/as dentro y fuera del trabajo a precios bajos y buena calidad.

\section{REFERENCIAS BIBLIOGRÁFICAS}

Akerlof, G. A., \& Kranton, R. E. (2000). Economics and Identity. Quarterly Journal of Economics, 115(3), 715-753. Recuperado de https://doi. org/10.1162/003355300554881

Albuja-Echeverría, W. S., \& Enríquez-Rodríguez, M. J. (2018). Análisis de la discriminación laboral hacia las mujeres en Ecuador 2007-2016. Con- 
vergencia Revista de Ciencias Sociales, 13. Recuperado de https://doi. org/10.29101/crcs.v0i78.9692

Anschau, A., \& Marin, S. R. (2017). Identidade (s) e liberdade de agência feminina: contribuições da economia social. Economia e Desenvolvimento, 28(2), 533-545. h Recuperado de ttps://doi.org/10.5902/1414650926492

Báez, M. A., Capua, M. de los Á. Di, \& Carosini, A. L. (2019). El debate entre la conciliación laboral y familiar en Paraguay: el caso de las Cooperativas de Ahorro y Crédito de Asunción, Año 2017. La Saeta Universitaria Académica y de Investigación, 7(1). Recuperado de http://www.unae.edu.py/ojs/ index.php/saetauniversitaria/article/view/125/121

Banco Mundial. (2019). República del Paraguay: Diagnóstico Sistemático de Paraguay. Recuperado de https://www.economia.gov.py/application/ files/7515/6641/5140/BIRF_Diagnostico_Sistematico_de_Paraguay-2018.pdf Bartalotti, O. A. C. (2007). Discriminação salarial por cor e gênero revisitada: uma abordagem de decomposição contrafactual utilizando regressões quantílicas. Fundação Getúlio Vargas. Recuperado de http://bibliotecadigital.fgv.br/dspace/handle/10438/1784

Becker, G. S. (1964). Human Capital: A Theoretical and Empirical Analysis, with Special Reference to Education. Recuperado de https://papers.ssrn.com/ sol3/papers.cfm?abstract_id $=1496221$

Becker, G. S. (1993). A Treatise on the Family. Cambrigde: Harvard University Press, 1993. Recuperado de https://www.hup.harvard.edu/catalog. php?isbn=9780674906990

Biagioni, D. (2006). Determinantes da mobilidade por classes sociais: teoria do capital humano e a teoria da segmentação do mercado de trabalho. Encontro Nacional de Estudos Populacionais-ABEP, (Xv), 19. Recuperado de http:// www.abep.org.br/publicacoes/index.php/anais/article/download/1501/1466

Brites, M., Marin, S. R., \& Almeida, F. (2019). Economia e identidade no século XXI: uma análise das contribuições de akerlof e kraton, sen e davis. Análise Econômica, 37(74), 203-225. Recuperado de https://doi.org/10.22456/2176-5456.75721

Caire, G., \& Becker, G. S. (1967). Human Capital, A Theoretical and Empirical Analysis with Special Reference to Education. Revue économique, 18(1), 132. Recuperado de https://doi.org/10.2307/3499575

Campante, F. R., Crespo, A. R. V., \& Leite, P. G. P. G. (2004). Desigualdade salarial entre raças no mercado de trabalho urbano brasileiro: aspectos regionais. Revista Brasileira de Economia, 58(2), 185-210. Recuperado de https://doi. org/10.1590/S0034-71402004000200003

Carrón, J. M., \& Silva, M. R. Da. (2007). La frontera Paraguay-Brasil, integración económica y desintegración social. Población y Desarrollo, 18(33), 20-39. Recuperado de http://revistascientificas.una.py/index.php/RE/article/view/744 
Casalí, P., \& Velásquez, M. (2016). Paraguay: panorama de la proteccion social, diseño, cobertura y financiamiento. ILO. Recuperado de https://www.ilo. org/wcmsp5/groups/public/---americas/---ro-lima/---sro-santiago/documents/publication/wcms_537219.pdf

Castillo, W. (2011). Discriminación Salarial por Género en el Perú: 2003-2009. Universidad de Chile. Recuperado de http://repositorio.uchile.cl/bitstream/ handle/2250/102513/cf-castillo_wm.pdf?sequence $=3 \&$ isAllowed $=y$

Castro Lugo, D., Huesca Reynoso, L., \& Zamarrón Otzuca, N. (2015). Discriminación salarial por género, en la industria manufacturera de la frontera norte de México, en el periodo 2005-2011. Nóesis. Revista de Ciencias Sociales y Humanidades, 24(1), 51-82. Recuperado de https://doi.org/10.20983/noesis.2015.1.2

Cavalieri, C., \& Fernandes, R. (1998). Diferenciais de salários por gênero e cor : uma comparação entre as regiões metropolitanas brasileiras. Revista de economia política, 18(1), 158-175.

CEPAL. (2019). Panorama social en América Latina 2018. Panorama Social de América Latina. Santiago de Chile: CEPAL. Recuperado de https://repositorio.cepal.org/bitstream/handle/11362/44395/11/S1900051_es.pdf

Cirino, J. F. (2008). Participação Feminina E Rendimento No Mercado De Trabalho: Análises De Decomposição Para O Brasil E As Regiões Metropolitanas De Belo Horizonte E Salvador. Universidade Federal de Viçosa. Recuperado de https://www.locus.ufv.br/bitstream/handle/123456789/111/ texto completo.pdf? sequence $=1 \&$ isAllowed $=\mathrm{y}$

Cirino, J. F., \& Lima, J. E. de. (2012). Diferenças de rendimento entre as regiões metropolitanas de Belo Horizonte e Salvador: uma discussão a partir da decomposição de Oaxaca-Blinder. Revista Econômica do Nordeste (Vol. 43). Recuperado de https://ren.emnuvens.com.br/ren/article/view/216

Contreras, D., \& Gallegos, S. (2011). Desigualdad salarial en América Latina: Una década de cambios. Revista de la CEPAL, 2011(103), 27-45. Recuperado de https://doi.org/10.18356/d4a2ded7-es

Corseuil, C. H., Fernandes, R., Menezes-Filho, N., Coelho, A. M., \& Santos, D. D. dos. (2002). Estrutura salarial: aspectos conceituais e novos resultados para o Brasil. IPEA. Instituto de Pesquisa Econômica Aplicada (Ipea). Recuperado de http://repositorio.ipea.gov.br/handle/11058/3038

Costa, E. M., Sousa, D. T. de, \& Guimarães, D. B. (2013). Decomposição dos diferenciais de rendimentos por cor e gênero no mercado de trabalho brasileiro: Uma análise por níveis ocupacionais nas regiões metropolitanas. Recuperado de http://www2.ipece.ce.gov.br/encontro/2015/ trabalhos/DECOMPOSIÇÃO DOS DIFERENCIAIS DE RENDIMENTOS POR COR E GÊNERO NO MERCADO DE TRABALHO BRASILEIRO.pdf 
DGEEC. (2000). Pobreza y distribución del ingreso en Paraguay. Recuperado de https://www.dgeec.gov.py/Publicaciones/Biblioteca/Pobreza_y_Distribucion/Pobreza_y_Distribucion_del_Ingreso.pdf

DGEEC. (2011). Censo Económico Nacional 2011 resultados oportunos. Recuperado de http://www.dgeec.gov.py/

DGEEC. (2019). EPHC 2018 Desigualdad de ingresos. Recuperado de www. dgeec.gov.py

DiNardo, J., Fortin, N. M., \& Lemieux, T. (1996). Labor Market Institutions and the Distribution of Wages, 1973-1992: A Semiparametric Approach. Econometrica, 64(5), 1001. Recuperado de https://doi.org/10.2307/2171954

Duflo, E. (2011). Women's Empowerment and Economic Development. (Working Paper No. 17702). Cambridge, MA: National Bureau of Economic Research. Recuperado de https://doi.org/10.3386/w17702

Ehrenberg, R. G., \& Smith, R. S. (2017). Modern Labor Economics: Theory and Public Policy. Taylor and Francis. Recuperado de https://doi. org/10.4324/9781315101798

Fernández-Huerga, E. (2010). La teoría de la segmentación del mercado de trabajo: Enfoques, situación actual y perspectivas de futuro. Investigacion Economica, 69(273), 115-150. Recuperado de https://doi.org/10.22201/ fe. $01851667 \mathrm{p} .2010 .273 .24253$

Fernández, J. (2015). Análisis de la Calidad del empleo en Paraguay. Población y Desarrollo, 21(41), 8-16. Recuperado de https://revistascientificas.una.py/ index.php/RE/article/view/673

Fortin, N., Lemieux, T., \& Firpo, S. (2011). Decomposition Methods in Economics. En O. Ashenfelter, \& D. Card (Eds.). Handbook of Labor Economics (Vol. 4, Cap. 1, pp. 1-102). Recuperado de https://doi.org/10.1016/S01697218(11)00407-2

Freire Seoane, M. J. G., \& Teijeiro Álvarez, M. (2010). Las ecuaciones de Mincer y las tasas de rendimiento de la educación. En Investigaciones de Economía de la Educación (Vol. 5, Cap. 14, pp. 285-304). Recuperado de https:// repec.economicsofeducation.com/2010zaragoza/05-14.pdf

Fuentes, J., Palma, A., \& Montero, R. (2005). Discriminación salarial por género en Chile: una mirada global. Estudios de economía , 32(2), 133-157. Recuperado de http://repositorio.uchile.cl/bitstream/handle/2250/127768/Jeanette_Fuentes.pdf? sequence $=1 \&$ isAllowed $=\mathrm{y}$

García, G. A., \& Badillo, E. R. (2018). Rationing of Formal Sector Jobs and Informality: The Colombian Case. Journal of International Development, 30(5), 760-789. Recuperado de https://doi.org/10.1002/jid.3310

Gelover, A. B., \& Garmendia, Y. R. (2005). El derecho a la no discriminación: una perspectiva internacional. El Cotidiano, (134), 78-88. 
Giménez Béliveau, V. (2011). La "triple frontera" y sus representaciones. Políticos y funcionarios piensan la frontera. Frontera Norte 23(46), 7-34. Recuperado de http://www.redalyc.org/articulo.oa?id=13619212001

Heckman, J. J. (1979). Sample Selection Bias as a Specification Error. Econometrica, 47(1), 153-161. Recuperado de https://doi.org/10.2307/1912352

Jann, B. (2008). A Stata implementation of the Blinder-Oaxaca decomposition. The Stata Journal 8(4), 453-479. Recuperado de https://core.ac.uk/download/ pdf/6442665.pdf

Juhn, C., Murphy, K. M., \& Pierce, B. (1991). Accounting for the Slowdown in Black-White Wage Convergence. In Workers and Their Wages: Changing Patterns in the U.S. (p. 107-143).

Kon, A. (2014). Mercado de trabalho, assimetrias de gênero e políticas públicas: considerações teóricas. RP3 - Revista de Pesquisa em Políticas Públicas, O(2). Recuperado de https://periodicos.unb.br/index.php/rp3/article/view/14599

Kritz, E. (2011). Un Mercado de Trabajo Segmentado. Recuperado de https://docplayer.es/13772236-Un-mercado-de-trabajo-segmentado-ernesto-kritz.html Lima, R. (1980). Mercado de trabalho: o capital humano e a teoria da segmentação. Pesquisa e Planejamento Econômico 10(1), 217-272. Recuperado de http:// repositorio.ipea.gov.br/handle/11058/3674

Machado, J. A. F., \& Mata, J. (2005). Counterfactual decomposition of changes in wage distributions using quantile regression. Journal of Applied Econometrics, 20(4), 445-465. Recuperado de https://doi.org/10.1002/jae.788

Melo, H. P. de, Considera, C. M., \& Di Sabbato, A. (2016). Dez anos de mensuração dos afazeres domésticos no Brasil. In N. Fontoura \& C. Araújo (Org.). Uso do Tempo e Gênero. (pp. 173-185). Recuperado de https:// www.gov.br/mdh/pt-br/navegue-por-temas/politicas-para-mulheres/ arquivo/area-imprensa/documentos-1/versaoartigopibafazeresdomesticossitespm.pdf

Menezes, W. F., Carrera-Fernandez, J., \& Dedecca, C. (2005). Diferenciações regionais de rendimentos do trabalho: uma análise das regiões metropolitanas. Estudos Econômicos (São Paulo), 35(2), 271-296. Recuperado de https://doi.org/10.1590/S0101-41612005000200002

Meza Martínez, C. A. (2018). Discriminación laboral por género: una mirada desde el efecto techo de cristal. Equidad y Desarrollo, (32), 11-31. Recuperado de https://doi.org/10.19052/ed.5243

Mincer, J. (1974). Schooling and Earnings. In J. Mincer. Schooling, experience, and earnings. (pp. 41-63). Cambridge, MA: National Bureau of Economic Research. Recuperado de https://www.nber.org/chapters/c1765.pdf

Mongelós Mayeregger, T. Y. (2015). Paraguay: la reproducción de las desigualdades de género en los fueros laborales. Igualdad que produce desigual- 
dad. Buenos Aires: CLACSO. Recuperado de http://biblioteca.clacso.edu. ar/clacso/clacso-crop/20150616112155/Arti_Mongelos_15062014.pdf

Monte, P. A. do, \& Gonçalves, M. F. (2006). A inserção ocupacional e os determinantes salariais das mulheres no mercado de trabalho. In Anais do XVI Encontro Nacional de Estudos Populacionais (Sessão Temática 28 pp. 1-20). Recuperado de http://www.abep.org.br/publicacoes/index.php/anais/ article/view/1796

Oaxaca, R. (1973). Male-Female Wage Differentials in Urban Labor Markets. International Economic Review, 14(3), 693-709. Recuperado de https:// doi.org/10.2307/2525981

OCDE. (2018). Estudio multidimensional de Paraguay: Volumen I. Evaluación inicial, (Serie Caminos de Desarrollo). París: OECD. Recuperado de https:// doi.org/10.1787/9789264301924-es

Oliveira, S. R. de, \& Piccinini, V. C. (2011). Mercado de trabalho: múltiplos (des) entendimentos. Revista de Administração Pública, 45(5), 1517-1538. Recuperado de https://doi.org/10.1590/S0034-76122011000500012

ONU MUJERES. (2015). Igualdad de género y principales brechas en paraguay. Recuperado de http://www.ciudadmujer.gov.py/application/ files/5114/9693/8060/Igualdad_de_Genero_y_principales_brechas_en Paraguay.pdf

Ortiz-Valverdi, N.-M. (2017). Discriminación salarial: brecha salarial entre hombres y mujeres del mercado laboral paraguayo. Población y Desarrollo, 23(44), 2-15. Recuperado de https://doi.org/10.18004/pdfce/2076054x/2017.023(44)002-015

Pereira, R. M., \& Oliveira, C. A. de. (2016). Os diferenciais de salário por gênero no Rio Grande do Sul: uma aplicação do Modelo de Heckman e da Decomposição de Oaxaca-Blinder. Redes, 21(1), 148. Recuperado de https://doi. org/10.17058/redes.v21i1.3583

Pinheiro, L. S. (2016). Determinantes da alocação de tempo em trabalho reprodutivo: uma revisão sobre os achados em pesquisas nacionais e internacionais In N. Fontoura \& C. Araújo (Org.). Uso do Tempo e Gênero (pp. 61-92). Recuperado de http://www.onumulheres.org.br/wp-content/ uploads/2016/04/uso_do_tempo_e_genero.pdf

PNUD-Paraguay. (2015). Pobreza, oportunidades económicas desiguales y género. Hipotesis para la discusion. Recuperado de https://www.latinamerica.undp. org/content/rblac/es/home/library/womens_empowerment/pobreza--oportunidades-economicas-desiguales-y-genero--hipotesis.html

PNUD. (2013). Empleo, Género y Desarrollo Humano. Recuperado de http://www. decidamos.org.py/mujeryeconomia/wp-content/uploads/2018/05/PNUDONU-MUJERES-Empleo-Genero-Desarrollo.pdf 
Psacharopoulos, G., \& Schultz, T. W. (1972). Investment in Human Capital. Economica, 39(155), 333-334. Recuperado de https://doi.org/10.2307/2551855

Rodríguez-Pérez, R., \& Castro-Lugo, D. (2014). Discriminación salarial de la mujer en el mercado laboral de México y sus regiones. Economía Sociedad y Territorio, 14(46), 655-686. Recuperado de https://doi.org/10.22136/ est002014392

Rodríguez-Pérez, R., Ramos-Lobo, R., \& Castro-Lugo, D. (2017). Brecha salarial por género en los mercados de trabajo público y privado en México. Panorama Económico, 25(2), 149-172. Recuperado de https://doi. org/10.32997/2463-0470-vol.25-num.2-2017-2105

Rodríguez Pérez, R. E. (2020). Diferencial salarial por género entre el sector público y privado formal-informal en México. Revista de Economía, Facultad de Economía, Universidad Autónoma de Yucatán, 36(93), 62-89. Recuperado de https://doi.org/10.33937/reveco.2019.108

Schultz, T. W. (1961). Investment in Human Capital. Recuperado 22 de setembro de 2019, de https://www.jstor.org/stable/i331528

Serafini, V. (2017). Trabajo Remunerado de las Mujeres desde un Enfoque de Género. CADEP. Recuperado de http://paraguaydebate.org.py/wp-content/ uploads/2018/01/Nota-Trabajo-Femenino.pdf

Serafini, V., \& Egas, M. I. (2018). Empleo Femenino en Parguay. Tendencias y Políticas Públicas. CADEP. Recuperado de http://www.cde.org.py/wp-content/uploads/2019/03/Empleo_Femenino_Paraguay.pdf

Servin, B., \& Masi, F. (2018). Territorios y empresas: Aproximación al desarrollo de las regiones en Paraguay. Recuperado de http://www.cadep.org. py/publicaciones-2/

Silva, N. de D. V., \& Kassouf, A. L. (2000). Mercados de trabalho formal e informal uma análise da discriminação e da segmentação. Nova Economia, 10(1), 41-77.

Silveira Braga, T., \& Rodarte, M. S. (2006). A inserção ocupacional e o desemprego dos jovens: o caso das regiões metropolitanas de Salvador e Belo Horizonte. Recuperado de http://www.sei.ba.gov.br/images/releases_mensais/pdf/ped/ped_estudos_especiais/artigo_jovens.pdf

Sinning, M., Hahn, M., \& Bauer, T. K. (2008). The Blinder-Oaxaca decomposition for nonlinear regression models. Stata Journal, 8(4), 480-492. Recuperado de https://doi.org/10.1177/1536867x0800800402

Stoikov, J., Doeringer, P. B., \& Piore, M. J. (1972). Internal Labor Markets and Manpower Analysis. Industrial and Labor Relations Review, 25(2), 273274. https://doi.org/10.2307/2521766 
STP. (2017). Diagnóstico para el ordenamiento territorial de Paraguay. Recuperado de http://www.stp.gov.py/v1/wp-content/uploads/2018/07/OTNTDR1y2-P3-DIAG.pdf

Tatei, F. (2011). Desigualdades no mercado de trabalho da América Latina: a discriminação por sexo entre os trabalhadores com ensino superior no Brasil e México. Biblioteca Digital de Teses e Dissertações da Universidade de São Paulo. Recuperado de https://doi.org/10.11606/D.84.2011.tde-18122012105148

Verbeek, М. (2007). A Guide to Modern Econometrics. ПРИКЛАДНАЯ ЭКОНОМЕТРИКА, 4(8), 125-132.

(C) 2021 por los autores; licencia no exclusiva otorgada a la revista Estudios económicos. Este artículo es de acceso abierto y distribuido bajo los términos y condiciones de una licencia Atribución-No Comercial 4.0 Internacional (CC BY-NC 4.0) de Creative Commons. Para ver una copia de esta licencia, visite http://creativecommons.org/licenses/by-nc/4.0 
